\title{
Ageing and the body: one African perspective
}

\author{
ENGUERRAN MACIA*, FATOU B. DIAL $\uparrow$, JOANN \\ M. MONTEPARE $\$$, FATOUMATA HANE* and \\ PRISCILLA DUBOZ*
}

\begin{abstract}
How do non-Western societies envisage the relationship between the body and ageing? The present work aimed to shed light on this question by exploring how adult men and women of different ages living in Dakar, Senegal, view their bodies. A quantitative methodology was selected, and this study was carried out on a sample of 1, ooo dwellers of the Senegalese capital, aged 20 and older. This sample was constructed using the quota method in order to strive for representativeness. Results indicate that appearance was highly important for Senegalese women and men, and for younger and older adults alike. As in Western cultures, beauty and youth were strongly connected. The large majority of Senegalese women and men were satisfied with their looks across the lifespan. However, older women were slightly less satisfied, consistent with the double standard hypothesis. Little discrepancy was found between felt age and chronological age throughout the entire lifecourse, arguing against an ageless self hypothesis in this African population. The mask of ageing hypothesis was also rejected, as men's and women's identification with their body did not diminish significantly across age. These observations from an African perspective call for greater attention to the ageing process in non-Western societies in order to challenge hypotheses developed in Western societies and understand more broadly the role of culture.
\end{abstract}

KEY WORDS - body image, mask of ageing, double standard, age identity, Senegal.

\section{Introduction}

The study of the body is not a new focus of investigation for the social scientists. Sociologists (Durkheim [1896] 1973), anthropologists (Mauss [1936]

* UMI 3189 Environnement, santé, sociétés, Université Cheikh Anta Diop, Dakar-Fann, Senegal.

$\dagger$ Institut Fondamental d'Afrique Noire, Université Cheikh Anta Diop, Dakar-Fann, Senegal.

$\$$ RoseMary B. Fuss Center for Research on Aging and Intergenerational Studies, Lasell College, Newton, Massachusetts, USA. 


\section{Enguerran Macia et al.}

$195^{\circ}$ ), as well as psychologists (Schilder [1950] 1968) have had a longstanding interest in the study of the body. However, the body had long been absent from scholarly work in social gerontology (Öberg 1996). Today this is no longer the case, and the body has become a heuristic interpretive lens through which the ageing process is viewed. Recent literature reviews attest to this (Hurd-Clarke and Korotchenko 2011; Roy and Payette 2012), as does the gamut of research emphasising corporeality, such as work focusing on transitions experienced by former ageing criminals (Sparkes and Day 2016) or the problems faced by older drivers (Gish and Vrkljan 2016). However, this work has focused almost exclusively on perspectives in Western societies, and most of the time on women (Hurd-Clarke and Korotchenko 2011). Thus, hypotheses concerning the ageing body, such as the double standard of ageing (Sontag 1979) and the mask of ageing (Featherstone and Hepworth 1991), have been developed within Western populations without considering their relevance in other cultural contexts.

How do non-Western societies envisage the relationship between the body and ageing? The present work aimed to shed light on this question by exploring several questions about the ageing body in adults living in the Senegalese capital, Dakar. Although there is a lack of research on ageing in Africa (e.g. Makoni and Stroeken 2002), and even less on the body (Chevé et al. 2014), ageing research has been emerging in Senegal and is used to inform the present study, as described below. The present study explored the body and the ageing process within the epistemological framework of Marcel Mauss ([1924] 1950: 285), who defines anthropology as 'the sum-total of the sciences that consider man as a living, conscious and sociable being'. Similarly, in Mauss' ([1924] 1950) framework, the body is viewed as a socially and culturally constructed biological object, a notion widely accepted by social science researchers (e.g. Andrieu 20o8; Boëtsch 2010). From an anthropological standpoint, the body and ageing are two biocultural research objects that, by their very essence, would benefit from being studied jointly.

\section{The body image of older adults: perspectives in a Western context}

For social scientists exploring images of the ageing body in Western societies, context is of prime importance (Biggs 2005; Kozar and Damhorst 2009; Laliberte Rudman 2015; Twigg and Majima 2014). Whether researchers evoke post-modernity (e.g. Featherstone and Hepworth 1991), late modernity (e.g. Öberg and Tornstam 1999) or the consumer society (Baudrillard 1970), all agree that social norms are becoming 
increasingly blurred in contemporary Western culture. The instability of social codes and the fluidity of rites of passage, according to Featherstone (1991), have shaken up one's identity moorings. In this context of confused identity structures, the population explosion and urbanisation have increasingly contributed to the promotion of one's individual appearance. Every day we pass judgement on people we do not know, on the basis of their appearance. The body has become 'the symbol of identity' (de Singly 2005), and 'working on one's appearance' (Corbin, Courtine and Vigarello 2005) is tantamount to working on one's identity. Moreover, given that Western societies value young, lean, muscular bodies, the visibly ageing body has become stigmatised (e.g. Le Breton 1990; Duret and Roussel 2003; Macia, Duboz and Chevé 2015). Working on and maintaining one's appearance has thus become a fight against ageing (Duret and Roussel 2003).

At the same time, the ageing body goes against the imperative of body control seen in Western societies (Tulle 2008). Michel Foucault's work helps better to understand the history and construction of these biopolitics. It was in the 18 th century that power began to exercise a new function: the organisation of society as an environment of physical wellbeing, optimum health and longevity (Foucault 1976). The base for this transformation, according to Foucault, is the preservation of the workforce. Since the eighteenth century, power has been exercised over active bodies, which must be educated better to control them. Today, keeping healthy and exerting control over one's body is a duty (Foucault 1976) and the ageing body, due to the biological consequences inherent in the processes of senescence, runs counter to this new categorical imperative. The hypotheses described below were developed within this general context of the imperative of youth and body control.

\section{Gender and body appearance: the double standard of ageing}

In Western societies, body image may hold different values for ageing women and men. Historically, the social value of women cannot be separated from their body and appearance, as for a long time their role was tied to bearing and raising children and satisfying men's sexual needs (Hurd 2000). Traditionally, the impossibility for women to assert their power in the public arena has reinforced the social valuation of their body: 'Being beautiful' was for many centuries the only way for them to climb the social ladder. Unlike men, they were therefore led to perceive their body as an object that has an essentially aesthetic aspect. Research by Öberg and Tornstam (1999) substantiates these remarks empirically: 82 per cent of the women believed that 'appearance is important', while 


\section{Enguerran Macia et al.}

only 6o per cent of the men believed this to be true, and these differences hold true across age. Ageing women must therefore face a 'double standard' (Sontag 1972) associated both with ageing and gender which dictates that women must fight the visible signs of the ageing process even harder than men (e.g. Schwaiger 2006). Most empirical studies of women's body image tend to support the double standard hypothesis, showing that the sense of satisfaction with one's appearance diminishes with age among women (e.g. Dumas, Laberge and Straka 2005; Grippo and Hill 2008; Grogan 2008), even if the body continues to remain a source of pleasure (Krekula 2007), and the importance of the body's functional aspect outweighs the aesthetic dimension (e.g. Tiggemann 2004). Interestingly, in their study of women in Sweden, Oberg and Tornstam (1999) found that the proportion of women satisfied with their body was increasing with age. However, their work examined women's views of their 'body', instead of 'appearance' (or 'looks'), which could partly explain the discrepancy, since the body encompasses appearance and functionality. At the same time, their findings point to the importance of considering more broadly the cultural context surrounding explorations of the body and ageing.

Studies conducted with men have yielded somewhat contrasting results (for a review, see Hurd Clarke and Korotchenko 2011). Halliwell and Dittmar (2003), for instance, found that men were not particularly affected by changes in their appearance with age, whereas Baker and Gringart (2009) found that men were increasingly dissatisfied with their appearance as they grow older, even if (or because) they were less involved in activities that helped them maintain an appearance consistent with the normative criteria-youth, slenderness and muscularity - of Western societies. Taken together, this work suggests that in Western societies, while body appearance is of concern to both ageing men and women, women tend to show more pervasive negative concerns.

\section{The mask of ageing}

The relationships between the ageing body and identity supply some of the liveliest debates in social gerontology today. In this regard, the "mask of ageing' hypothesis, developed by Featherstone and Hepworth (1991), has been influential. Building on the notion of ageless self among older adults (Kaufman 1986), these researchers suggested that biological ageing-visible and experienced-could bring about an ontological conflict. In old age, the self - that is hence ageless - remains trapped in a body that is deteriorating both functionally and aesthetically. Corroborated by several studies (e.g. Hurd Clarke 2001; Morell 2003), these researchers consider that the ageing body thus becomes a locus 
of conflict in seeking a coherent identity in old age. While identity choices appear limitless in post-modern societies (Bauman 1995; Turner 1994), the identity quest of older adults is gradually limited by the body. This conflict between mind and body - can only be resolved as ageing becomes more and more visible and binding, through the dissociation of self and body.

Other theorists have argued that the mask of ageing hypothesis is incompatible with a phenomenological approach (e.g. Tulle 2008). Drawing on qualitative in-depth interviews with French women, Macia (2013) believes that the claim to be younger on the inside than what the body exhibits on the outside is a positive, comforting illusion that enables one to demonstrate to others as well as to oneself that one is in harmony with the standards of Western societies. Through this discourse, visibly older French women wish to show that they are not old on the inside, with all the derogatory stereotypes associated with this categorisation: 'useless', 'diminished', 'aggressive', 'nasty' or 'selfish' (Macia 2013).

\section{The African context and research questions}

\section{Senegal and Dakar}

Senegal, located in the westernmost part of sub-Saharan Africa, is one of the least developed countries in the world, ranked 17oth (out of 188) in the latest United Nations Human Development Report (United Nations 2016). The Senegalese population is very young: 42 per cent of the country's 13.5 million inhabitants in 2013 were under age 15 and scarcely 3.5 per cent were over 65 (Agence Nationale de la Statistique et de la Démographie (ANSD) 2014). It is also very poor, with 31 per cent of the population living in a situation of 'severe poverty' according to the multidimensional indicator used in the most recent Human Development Report (United Nations 2016).

Dakar is the country's political and economic capital, with 23.2 per cent of the population on 0.3 per cent of its territory (ANSD 2014). The capital differs significantly from the rest of the country, as the Dakar population is the oldest and the most educated in Senegal (ANSD 2014). 'Only' 38 per cent of Dakar inhabitants over age 10 are illiterate, whereas the illiteracy rate reaches 55 per cent for the country overall. In 2004, 81 per cent of Dakar households had electricity, while this was true of only 47 per cent of Senegalese households overall (Ndiaye and Ayad 20o6). The growth of a market economy and middle classes, the development of a bureaucracy and even the dominance of scientific rationality over traditions and values are additional factors reinforcing the idea that Dakar society is a modern society (Werner 1997). 


\section{Older adults in Dakar}

In an African context where deference to elders constitutes one of the pillars of social and family organisation (Balandier 1974), older adults are without doubt the keepers of traditional values and the guarantors of the perpetuation of community habitus in Senegal (Macia et al. 2015a). Despite the low demographic weight of older adults in Dakar, they make up a large percentage of heads of households $(32 \%)$, and 40 per cent of Dakar inhabitants live in a household led by an older adult (Antoine 2007). This factor suggests that older adults still maintain authority as heads of households and hold responsibility in major decisions.

These facts help to explain why the social representations of magget (older adults in Wolof) are mainly positive in Dakar (Macia et al. 2015a). In turn, older adults are the age group with the highest level of subjective wellbeing (Macia et al. 2015b). The social value associated with old age also contributes to the fact that older adults in Dakar far less frequently wish to be younger than they are than Westerners of the same age (Macia et al. 2012).

\section{Research questions}

While no research has been conducted in Senegal on the ageing body, there have been a few groundbreaking studies on other aspects of the body in Senegal. In particular, the edited volume assembled by Chevé et al. (2014) around the wrestler's body-wrestling is the national sport in Senegal - revealed how musculature was an important criterion of masculinity. The study of the emergence of obesity and modern stigmas by Cohen et al. (2012) also showed the tensions between tradition and the importance of appearance as a recent consequence of Senegal's modernisation.

In light of the Western research literature, the context of Dakar, and the dearth of literature on ageing and the body in Africa, the research questions raised in the present study were developed around five themes.

1. The importance of appearance. To what extent is appearance important for men and women in Dakar?

2. Appearance, gender and ageing. At what age do men and women prefer their physical appearance? To what extent do adults in Dakar worry about how their looks will change as they age, and does change worry women more than men?

3. The double standard of ageing. To what extent are men and women in Dakar satisfied with their appearance? Are men more satisfied than women, and do their views differ with age?

4. Ageless self. Is there a discrepancy between chronological age and felt age in Dakar and does this discrepancy increase with age? 
5. Mask of ageing. To what extent do adults in Dakar identify with their body and does this identification change with age?

\section{Materials and methods}

\section{Respondent sample}

The present study was conducted from February to August 2015 on a sample of 1, ooo individuals age 20 and older. The sample was constructed using the combined quota method in order to strive for representativeness of the population age 20 and older living in the department of Dakar. Data from ANSD dating from the most recent census were used. In 2013, the population of the department of Dakar was 1,146,053, including 725,373 adults age 20 and over. The quota variables used were gender (male/female), age $\left(2 \mathrm{O}^{-29}, 3^{\mathrm{O}-39}, 4 \mathrm{O}^{-} 49,5^{\mathrm{O}}-59\right.$, 6o and over, with an upper age limit of 90 years) and town of residence. The towns were grouped by the four arrondissements making up the department of Dakar: Plateau-Gorée (five towns), Grand Dakar (six towns), Parcelles Assainies (four towns) and Almadies (four towns). Practically, this method requires constructing a sample that reflects the proportions observed in the general population. For example, according to the last census, women age 20-29 living in town of Medina (arrondissement of Plateau-Gorée) represented 1.5 per cent of the population age 20 and older living in the department of Dakar. The sample has been constructed so as to reflect this proportion and include 15 women age 20-29 living in this town. In order to limit bias associated with the sampling method, the investigators worked at different times of day (and sometimes on Saturday and Sunday) and began their investigation in each town of residence from different starting points each day. Pregnant women were excluded from the sample. The final sample consisted of 984 adults which included 494 men and 490 women.

Eight trained investigators (PhD students in Sociology and Medicine) started out each day from different points in each town to interview individuals in Wolof or French. They stopped at every third home, i.e. the dwelling behind every third front door or entrance gate. Investigators interviewed men and women in each age group to meet the quotas. Only one person was selected as a respondent in each home.

The data were collected through directed, individual interviews carried out face-to-face using a questionnaire. In-person interviews ranged from 45 minutes to more than one hour and 30 minutes, depending on respondent availability and desire to talk. This methodology enables relationships of trust to develop with the respondents and allows for a wide range of 
information to be gathered. The present study focused on questions directly related body image, age and health.

The study was approved by the National Ethics Committee for Health Research of Senegal (protocol SEN13/67, number 0272). Research was conducted in accordance with the Declaration of Helsinki. Written informed consent was obtained from participants.

\section{Measures}

Body image was assessed using four questions adapted from Öberg and Tornstam's study (1999) of body image among men and women of different ages in a Swedish sample. These questions were similar in general content to measures used in other studies which have examined agerelated body images and age perceptions in Western samples (e.g. Montepare 2006). The parallel back-translation procedure described by Vallerand (1989) was used to translate the questionnaire into Wolof, the language spoken by everyone in the Senegalese capital. Specifically, participants were asked whether they 'fully agreed', 'rather agreed', 'rather disagreed' or 'did not agree at all' with the following statements: (a) 'My appearance is important to me'; (b) I worry about how my physical appearance will change as I grow older; (c) 'I am satisfied with my appearance'; (d) I feel that my body reflects who I really am'. To determine to what extent youth is associated with beauty, one question was added: 'At what age were you most satisfied with your physical appearance?' Self-rated health was measured using a question with five possible answers: 'Overall, would you say that your health is excellent, very good, good, mediocre or poor?' Finally, two questions concerned age. The first, emphasising the medical aspect of our study so as to convince participants to tell us their real chronological age, was: 'For medical reasons, we need to know your age. Could you please tell us?' Perceptions of felt age were assessed with the question: 'Deep down inside, what age do you feel?'

\section{Analyses}

Age-related analyses were done comparing responses across the five age groups used in the sample selection $(20-29$ years, $\mathrm{N}=413$; 30-39 years, $\mathrm{N}=266 ; 40^{-}-49$ years, $\mathrm{N}=156 ; 5^{\mathrm{o}}-59$ years, $\mathrm{N}=87,60-90$ years, $\mathrm{N}=62$ ). Answers to body image questions were dichotomised for chi-square analyses and illustrations ( $\mathrm{o}=$ 'rather disagreed' and 'did not agree at all'; $1=$ 'fully agreed' and 'rather agreed'). Student's $t$-test, analysis of variance (ANOVA) and non-parametric correlations were also used to answer our research questions. 


\section{Results and discussion}

Given the exploratory nature of the study, results are presented along with commentary for greater cohesion.

\section{The importance of appearance}

Figure 1 shows that the vast majority of women (93.9\%) and men $(93.1 \%)$ living in Dakar indicated that appearance was important (i.e. 'fully agreed' or 'rather agreed' with the sentence 'my appearance is important to me'). Indeed, this level of reported importance was even more than that reported by Swedish women $(82 \%)$ and Swedish men $(60 \%)$ interviewed by Öberg and Tornstam (1999).

Why might appearance be so important to Senegalese men and women? Several first-hand observations by the researchers provided insights for further empirical consideration. Anyone who has lived in Senegal has noticed the great attention men and women pay to their appearance. Attention is paid especially to clothing-which is an integral part of bodily appearance across cultures (e.g. Twigg 2004). In the unpaved streets of the capital Dakar, it is virtually impossible to determine people's occupations by their appearance as is seen in France (Bourdieu 1979), and Senegalese women who employ domestic help often joke that their employees leave their home better dressed than they are.

In Dakar society, which is poor, collectivistic and urban, it is vital not to appear destitute: the expression sagal sa bop (do your appearance justice in Wolof) illustrates this focus on one's appearance. Looking destitute necessarily reflects on the lineage, and individuals-like those in the West - are eager to save face (Goffman 1974). Moreover, given that city living fosters chance encounters, anyone can meet someone he or she knows at any time, and that person could peddle unflattering remarks if one's appearance was unbecoming. These observations may offer one perspective to explain the considerable importance individuals attached to appearance in Senegal. Certainly further empirical validation of this speculation is warranted.

\section{Appearance, gender and ageing}

Figure 2 shows trends for the mean age for which women and men preferred their appearance. The pattern of responses across the age groups indicated that beauty was highly associated with youth among both women and men in Dakar. For all age groups, the age at which individuals preferred their appearance was younger than their actual age. Moreover, 
824 Enguerran Macia et al.

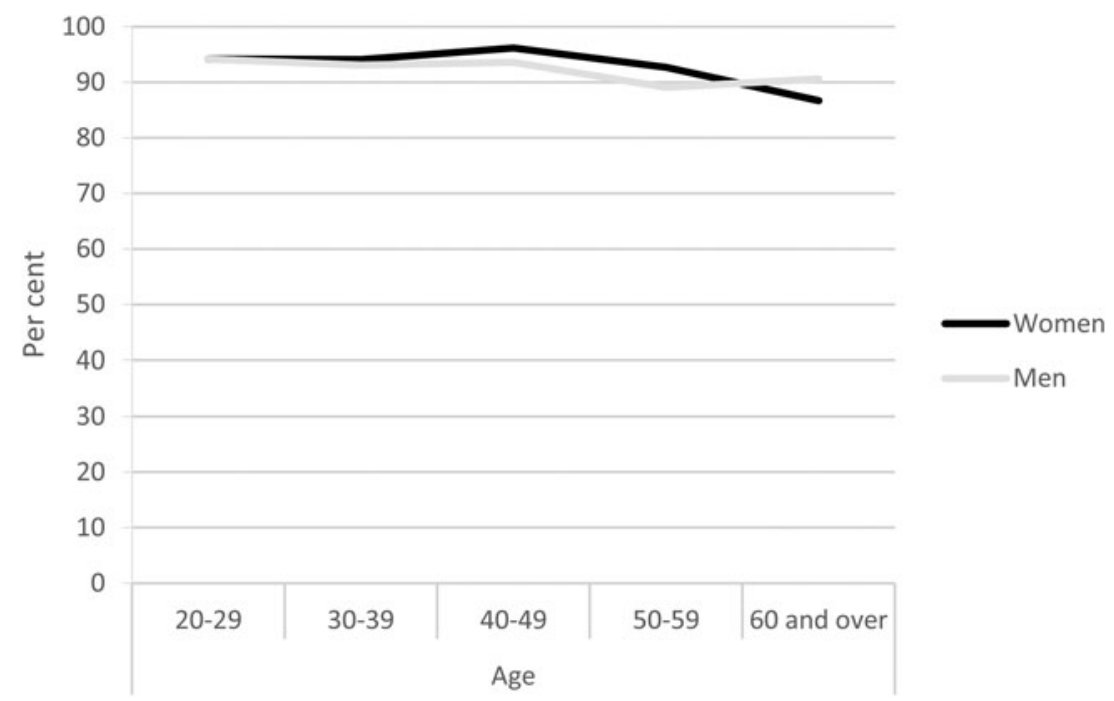

Figure 1. My appearance is important to me.

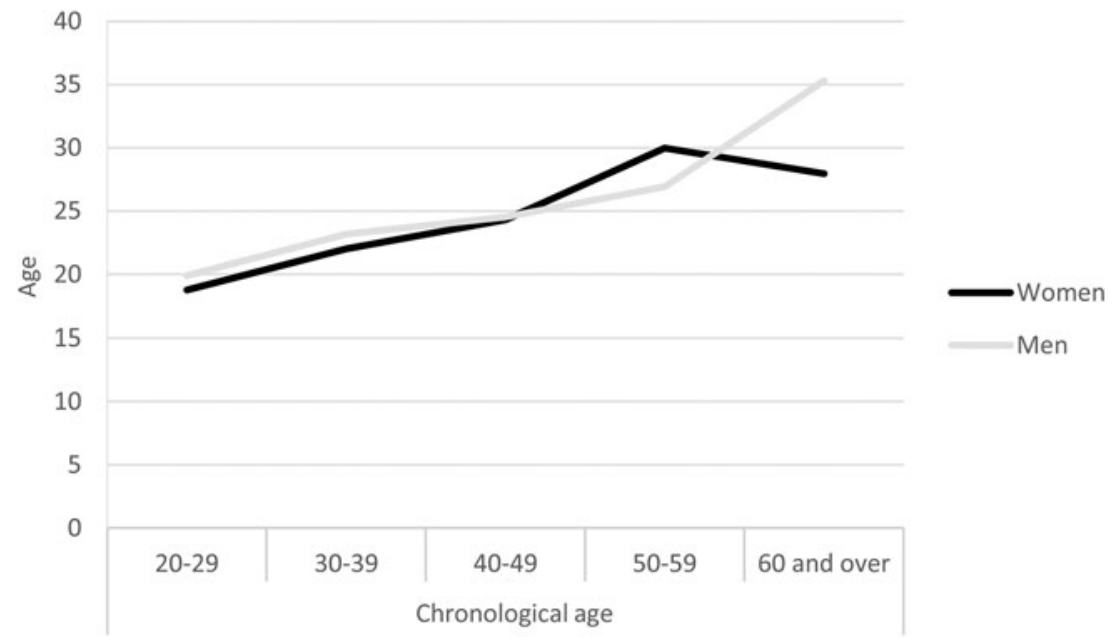

Figure 2. Age for which people preferred their appearance.

the differences become even greater with advancing age. More specifically, ANOVA results revealed significant differences across age groups among men $\left(F(493)=5^{1.00} ; p<0.001\right)$ and among women $(F(489)=37.61 ; p<$ o.001). An inspection of the actual age group differences showed that whereas younger adults (20-29 years) preferred their looks at only a few years younger (men: $19.9 \pm 4.1$ years; women: $18.8 \pm 3.5$ years; $t=3.04 ; p<$ 
0.01), the difference was much greater among older adults. In fact, among the age 60 and over, men said they preferred their appearance at age $35.2 \pm$ 12.1 years and women at age $28.0 \pm 8.9(t=2.73 ; p<0.01)$. In addition, the ideal age at which the participants preferred their appearance was not greater than 30 years among women, and at most 35 years for men. On the whole, the age at which men preferred their looks was older (23.2 \pm 7.3 years $)$ than women $(22.0 \pm 7.4$ years; $t=2.37 ; p<0.05)$.

The tendency for men and women to view their younger years and looks to be more preferred resonates with the attention given towards a youthful appearance that has been documented in the Western research literature on body image in women (e.g. Hurd Clarke and Griffin 2008) and in men (e.g. Slevin 2008). Moreover, the fact that the age at which men preferred their looks was older than women also showed that the youth imperative applied more to women than men, as in Western societies (e.g. Schwaiger 2006).

Figure 3 shows that a significant proportion of men and women in Dakar also said they were worried about how their appearance would change as they grow older (i.e. 'fully agreed' or 'rather agreed' with the sentence 'I worry about how my physical appearance will change as I grow older'). On the whole, women $\left(5^{1.4 \%)}\right.$ were more worried about aesthetic body changes than men $\left(40.3 \% ; \chi^{2}(1\right.$ degree of freedom $\left.)=12,31 ; p<0.001\right)$. This rate increased gradually among women, starting at 44 per cent among the younger and reaching 70 per cent among older women $\left(\chi^{2}(4)=10.61 ; p<0.05\right)$. The curve was more uneven among men. The proportion of men who said they worried about how their looks will change with age did not vary significantly through the lifecourse $\left(\chi^{2}(4)=5.71\right.$; not significant (NS)).

These results further indicate that youth is closely associated with beauty in Dakar, and this holds true even more among women than among men. Dakar aesthetic standards are thus close to Western aesthetic standards that value youth, a beauty criterion that applies particularly to women in Western societies (e.g. Hurd Clarke and Korotchenko 2011) as in Dakar. As noted beforehand, a number of factors may account for the pervasive association of youth with beauty across cultures, especially among women. It is also of interest to consider distinctive local cultural reasons that may drive this view. For example, it may be that youthful beauty is important for Dakar women because it enables them to enter into a socially beneficial marriage (Dial 2008). The possibility for men to marry a younger second, third or fourth woman may also play a role in the discrepancy between genders according to aesthetic consequences of the ageing process.

It is of interest to note that the present results showed that the Senegalese population was more worried about changes in their looks than the Swedish 


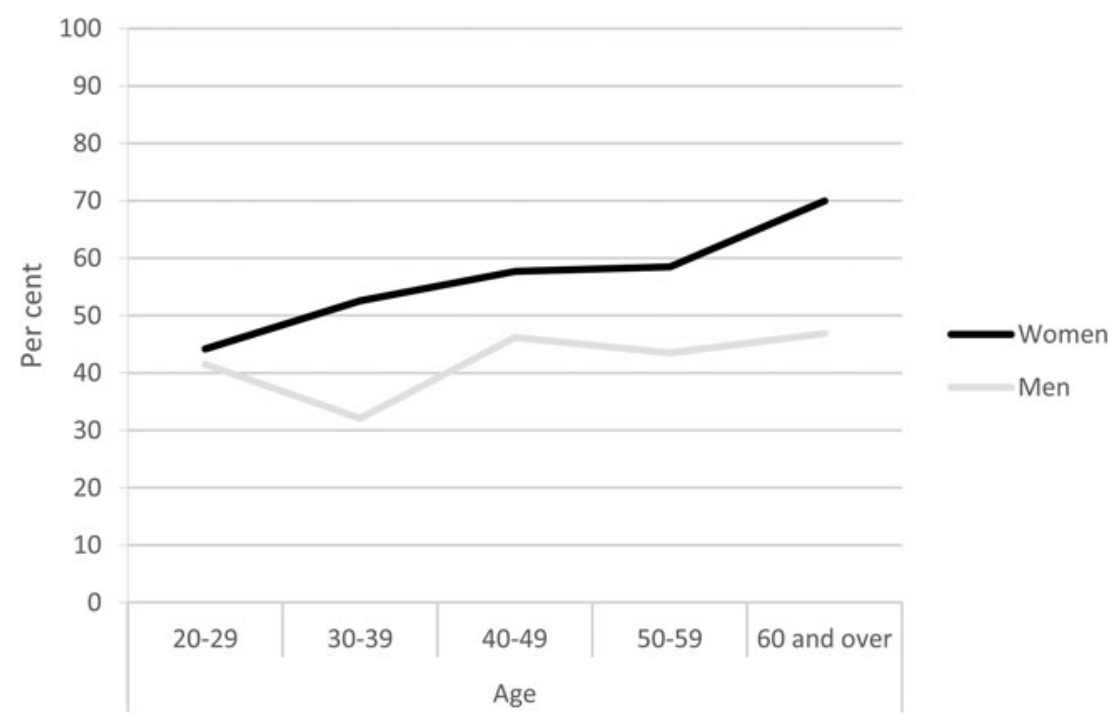

Figure 3. I worry about how my physical appearance will change as I grow older.

population studied by Öberg and Tornstam (1999). Only 27 per cent of Swedish women and 16 per cent of Swedish men said they worried about how their looks would change as they grew older, compared to $5^{1.4}$ per cent of women and 40.3 per cent of men in Dakar. Why such a difference? One insight comes from considering that in a country with proportionally so few older adults such as in Senegal (United Nations 2016), there is far less diversity among ageing body types than in Western countries. As well, techniques used to conceal visible signs of ageing or to repair the ageing body are not particularly developed in Senegal. For instance, moisturising creams used to restore volume to the skin are expensive compared to household income and therefore cannot be used by many women. Even more important is the high cost of surgical repairs to the body. Whether the problem is to install a dental crown, or have a hip or knee replacement or any other surgery that is commonly performed in Western societies, the opportunity for Dakar inhabitants to undertake such surgery is limited, at once because health-care provision is limited (Duboz et al. 2015) and because such operations are generally too costly for the population. Thus, in Dakar, life's accidents usually leave their mark on the body, much more so than in Western societies where they are more easily concealed and repaired. All of these considerations help to explain, at least in part, why the Dakar population seems so concerned about changes in their appearance with age. 


\section{The double standard of ageing}

The vast majority of Dakar men $(85.2 \%)$ and women $(82.2 \%)$ were satisfied with their appearance (i.e. 'fully agreed' or 'rather agreed' with the sentence 'I am satisfied with my appearance'). While satisfaction among Dakar men was very close to that of the Swedish men studied by Öberg and Tornstam (83\%), women in Dakar showed a much higher satisfaction rate than did Swedish women $(65 \%)$, who showed a relatively high degree of satisfaction, even for women in Western cultures. Why is that? One possibility is that the appearance standards in Senegal are less stringent than in Western societies. In the context of Dakar, it would seem that social norms - which on the whole remain strict unlike in the West where they are becoming blurred (Featherstone 1991)-may contribute to leaving more room for variability as regards the body.

The present results moreover indicated that women were not significantly less satisfied with their appearance than were men $\left(\chi^{2}(1)=1.60\right.$; NS). However, if satisfaction was relatively high throughout the lifecourse among Dakar men $\left(\chi^{2}(4)=4.65\right.$; NS), there was a marginally significant difference between younger and older women's satisfaction $\left(\chi^{2}(4)=9.31 ; p=\right.$ $0.054)$. More precisely, 88 per cent of women between 20 and 29 years of age were content with their looks, compared to only 70 per cent of women age 60 and over. These results, combined with those on youth and beauty, tend to support the double standard hypothesis, even if further qualitative investigation is necessary to confirm this tendency (Figure 4).

\section{Ageless self}

Across the whole sample, average felt age ( $34.7 \pm 13.4$ years) was only one year younger than the average chronological age of men and women $(35.7 \pm 13.2$ years $)$. Over three-quarters of the sample $(75.5$ per cent $)$ had a felt age that exactly matched their chronological age; only 18.2 per cent of them felt younger than they actually were. Figure 5 illustrates the similarity between chronological age and felt age throughout the lifecourse.

These results corroborate those found by Macia et al. (2012) regarding the age identity of people age $5^{\mathrm{o}}$ and over in Dakar. In Dakar, it thus seems that the self is not ageless, as a body of qualitative research using Western samples has shown (for a review, see Hurd Clarke and Korotchenko 2011). The methodology used to study the ageless self - quantitative or qualitative - could lead to different results and the present researchers' experience in the field tends to indicate that such discursive strategies (Macia 2013) exist in the Senegalese capital as well. They seem 


\section{Enguerran Macia et al.}

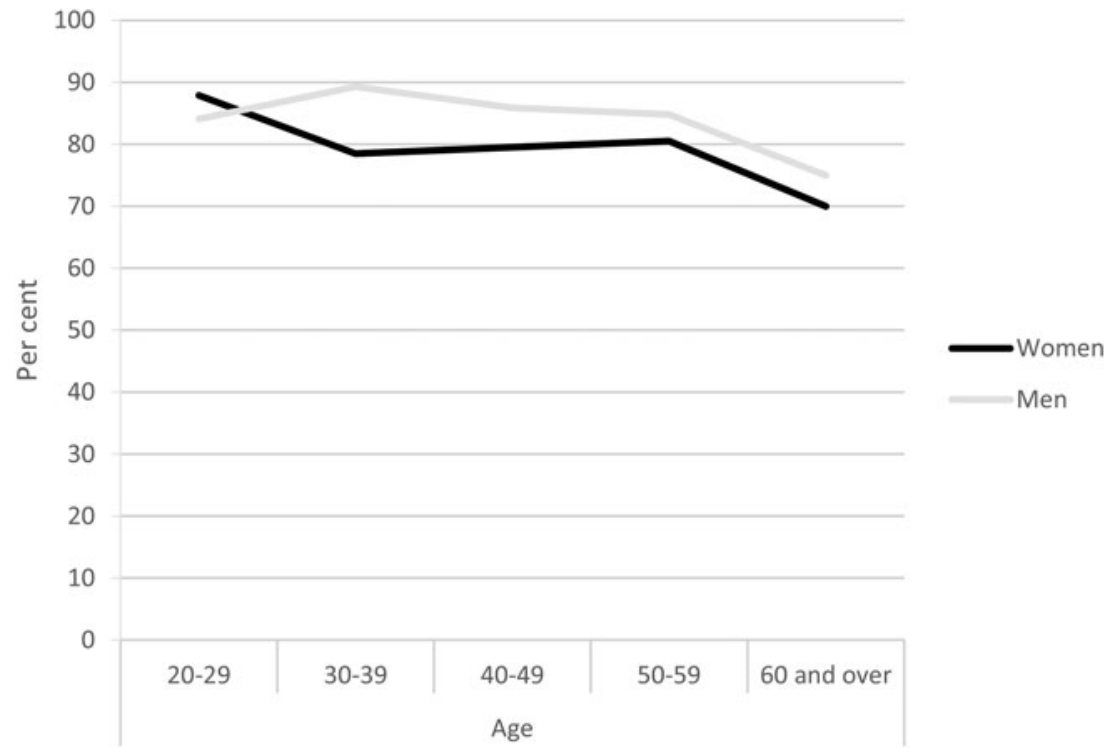

Figure 4. I am satisfied with my appearance.

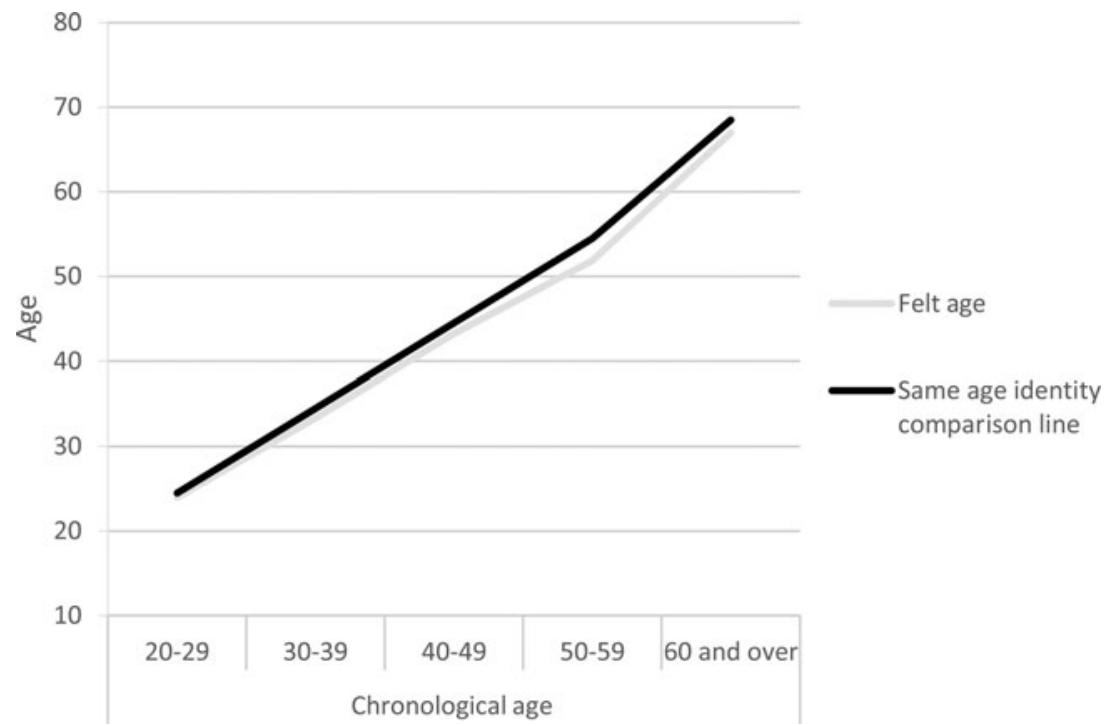

Figure 5. Real age and felt age.

less common, nevertheless, than in Western societies, as attested by the far higher percentage of people who say they feel younger than their chronological age (Diehl et al. 2014; Montepare 2006). At the same time, as previously discussed, the context of Dakar makes it difficult to conceal or repair 
the body's ageing. It thus seems difficult for older adults - whose lifecourse is often imprinted on the body - to ignore their corporeality.

Given the mostly positive representations of elders in Dakar (Macia et al. $2015 a$ ), men and women may not feel the need to shield themselves from age-related categorisations and assume younger age identities, as is the case in more ageist Western cultures. In other words, across age, men and women in Dakar do not seem to feel the need to create an ageless identity to prove to themselves and others that the stereotypes and stigma associated with age (negative in the West) do not, or will not, apply to them.

\section{Mask of ageing hypothesis}

Consistent with present evidence challenging the notion of an ageless self in Dakar, men and women reported that for the most part, they felt that their body reflected who they really were, as seen in Figure 6. Overall, 72 per cent of the sample fully or rather agreed that they felt that their body reflected who they were $(71.6 \%$ of women, $72.3 \%$ of men). Identification with the body did not vary significantly with age among women $\left(\chi^{2}(4)=4.26\right.$; NS) nor among men $\left(\chi^{2}(4)=6.39\right.$; NS).

Why might this be the case? In Dakar, the feeling of being well represented by one's body was not correlated with age ( $\rho$ (Spearman) $=-0.008$; NS), but it was significantly correlated with self-rated health $(\rho=0.127 ; p<0.01)$. Poor health thus goes along with a dis-identification between the individual and the body. Thus, it would seem that the body can break down and prevent individuals from engaging in activities that fulfil them and/or through which they are recognised by their community. The distinction between the third and the fourth age in Western society is partly based on these transformations of the body (Gilleard and Higgs 2011). In Dakar, however, this disconnect with the body may affect all age groups to a greater extent than in Western societies where body fixes are more accessible. More than elsewhere, the body can break down at any age and thus be presented, and sometimes experienced, as misrepresenting the self. This disconnection is consistent with the notion that the self is shaped at least partly through other people's social perceptions (Goffman [1963] 1975). In other words, the self is constructed in relation to others, through intersubjectivity. A person suffering from poor health, physical disability or even visibly very old age may not wish to present the self though this lens. At other moments, the physically disrupted self will nevertheless remain, for others as well as for the person as one cannot blot out the body. Thus, more than simply growing old, it would seem that functional problems of the body come into play in the discursive strategies used by Senegalese people who say they do not identify with their body. In short, 
83o Enguerran Macia et al.

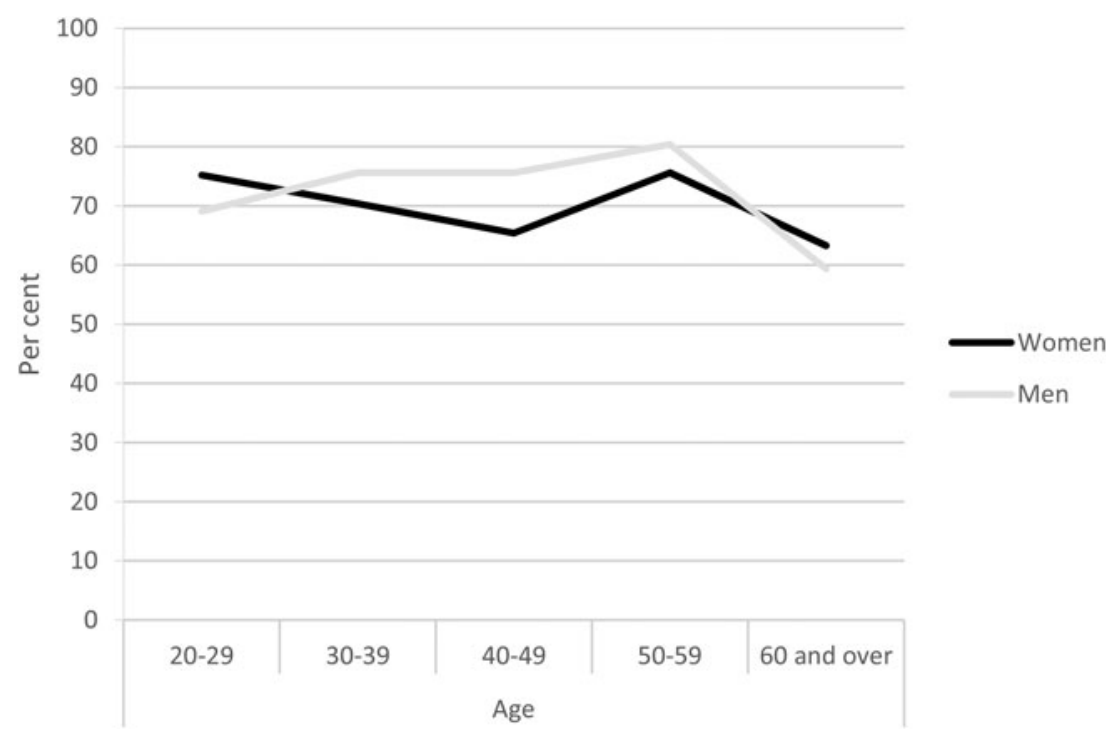

Figure 6 . I feel that my body reflects who I really am.

more than age identity, an identity related to the body's functionality emerges from our African perspective.

\section{Conclusion}

To conclude, we begin by briefly answering our research questions. Were looks important in this African sample? Yes, appearance was highly important in Dakar for women and men, and for younger and older adults alike. It is most likely essential for these Senegalese men and women to put on a decent appearance - of the self for oneself, as well as for one's social group - in a collectivist society characterised by endemic poverty. What was the relationship between age and appearance? As in Western cultures, beauty and youth were very much connected in Dakar. Senegalese women worried more about their appearance than men with advancing age, but both seemed very concerned about these body changes. The lesser opportunities to conceal and repair the body may similarly play a role in this dread of the processes of senescence. Is there a double standard of ageing? Also as in Western societies, the tendency of older women to be less satisfied with their appearance than younger ones tend to support the double standard hypothesis. Is the self ageless? Contrary to patterns observed in Western samples, felt age followed chronological age very closely throughout the entire lifecourse, arguing against the ageless self 
hypothesis in the Senegalese capital. Is there a mask of ageing? No, the mask of ageing hypothesis was also rejected, as men's and women's identification with their body did not diminish significantly across age in Dakar. Thus, the ageing body-self hypothesis seems empirically more probable than the ageless self hypothesis in an African perspective of the body.

The present research paves the way for new studies on the ageing body beyond the Western context, especially with respect to certain frameworks in the contemporary literature. In particular, the present observations call for greater attention to the ageing process in non-Western societies. Such approaches are fundamental to understand the role of culture and to challenge hypotheses developed in Western societies. Indeed, our results have shown that the ageless self may only be a discursive strategy temporarily brought into play through culturally focused social interaction. In accordance with phenomenology, the self can only be corporal, and in the framework of social gerontology, where age matters by definition, it is necessarily ageing. The present research also helps to define better how one African society constructs the ageing body. With respect to Western societies, it produces less strict body standards. The imperatives of youth and biomedical control of the body are less stringent. This context presents the advantage of being less stigmatising with respect to the ageing body-self, but it may also not be restrictive enough to prepare for an increasingly ageing population. Expanded cross-cultural research should gradually make it possible to clarify further the relationships between the ageing body-self and the context within which it is constructed.

Moving forward, several considerations would be of benefit in exploring African perspectives in more depth. Building on the present methodology, more qualitative interviews with men and women would provide an opportunity to evaluate the explanations offered here. In this work, it would be of interest to consider if the use of terms such as appearance or body lead to different observations and insights, and to understand better if wider influences - as advertising, marketing, globalisation - impact more on women than men, partly explaining the double standard of ageing in Dakar. Indeed, a qualitative study is currently under way by the present researchers that distinguishes these notions more clearly by considering bodily appearance on the one hand, and its functionality, on the other, along with how biological and social processes interact in shaping personal images and self-identification. Lastly, as is the case with all explorations of ageing and gender, one must consider potential cohort effects, especially moving forward as Senegal evolves culturally from the influences of advancing modernity. 


\section{$83_{2}$ Enguerran Macia et al.}

\section{Acknowledgements}

The authors wish to thank the Senegalese interviewers who participated in this study, particularly Babacar Kane and Amadoune Gueye, our team leaders. This work was supported by the National Center for Scientific Research, France (PEPS 'Ecological Health'; http://www.cnrs.fr/inee/outils/PEPS2014.htm). This study was approved by the National Ethics Committee for Health Research of Senegal (protocol SEN13/67, number 0272). E. Macia contributed to the conception, design, analysis, interpretation of data and the drafting of the article. F. B. Dial, J. M. Montepare and F. Hane contributed to the analysis, interpretation of data and revised the paper critically for important intellectual content (theoretical aspects). They also wrote parts of the paper. P. Duboz contributed to the conception and design of the study, and the drafting of the article. All authors approve the submitted version of the article. The authors declare no conflict of interest.

\section{References}

Agence Nationale de la Statistique et de la Démographie (ANSD) 2014. Recensement général de la population et de l'habitat, de l'agriculture et de l'élevage (RGPHAE 2013). Available online at http://www.ansd.sn/ressources/rapports/Rapport-definitifRGPHAE2013.pdf [Accessed 8 February 2013].

Andrieu, B. 2008. Devenir hybride. Presses Universitaires de Nancy, Nancy, France.

Antoine, P. 2007. Les relations intergénérationnelles en Afrique. Approche plurielle. Ceped, Paris.

Baker, L. and Gringart, E. 20o9. Body image and self-esteem in older adulthood. Ageing Eं Society, 29, 6, 977-95.

Balandier, G. 1974. Anthropo-logiques. Presses Universitaires de France, Paris.

Baudrillard, J. 1970. La société de consommation. Denoël, Paris.

Bauman, Z. 1995. Life in Fragments: Essays in Postmodern Morality. Blackwell, Oxford.

Biggs, S. 2005. Beyond appearances: perspectives on identity in later life and some implications for method. Journal of Gerontology: Social Sciences, 6o, 3, $\mathrm{S}_{1} 18-28$.

Boëtsch, G. 2010. Anthropologie et beauté. In Boëtsch, G., Le Breton, D., Pomarède, N., Vigarello, G. and Andrieu, B. (eds), La belle apparence. CNRS Editions, Paris, $35^{-44}$.

Bourdieu, P. 1979. La distinction. Critique sociale du jugement. Editions de Minuit, Paris. Chevé, D., Wane, C. T., Barthélémy, M., Kane, A. W. and Sow, I. 2014. Corps en lutte. L'art du combat au Sénégal. CNRS Editions, Paris.

Cohen, E., Ndao, A., Gueye, L., Boëtsch, G., Pasquet, P. and Chapuis-Lucciani, N. 2012. La construction sociale du corps chez les sénégalais dans uncontexte de transition des modes de vie. Antropo, 27, 81-6.

Corbin, A., Courtine, J.-J. and Vigarello, G. 2005. Histoire du corps. Seuil, Paris.

de Singly, F. 2005. Le Soi dénudé: sur l'inscription corporelle de l'identité intime. In

Bromberger, C., Duret, P., Kaufmann, J.-C., Le Breton, D., de Singly, F. and Vigarello, G. (eds), Un corps pour soi. Presses Universitaires de France, Paris, $115-38$.

Dial, F. B. 2008. Mariage et divorce à Dakar. Itinéraires féminins, Karthala, Paris.

Diehl, M., Wahl, H., Barrett, A., Brothers, A., Miche, M., Montepare, J. M., Westerhof, G. and Wurm, S. 2014. Awareness of aging: theoretical considerations of an emerging concept. Developmental Review, 34, 2, 93-113. 
Duboz, P., Gueye, L., Boëtsch, G. and Macia, E. 2015. Accès aux soins à Dakar (Sénégal): fréquence, type de soignants et maladies chroniques non transmissibles. Médecine et Santé Tropicales, 25, 2, $165^{-71}$.

Dumas, A., Laberge, S. and Straka, S. 2005. Older women's relations to bodily appearance: the embodiment of social and biological conditions of existence. Ageing E् Society, 25, 6, 883-902.

Duret, P. and Roussel, P. 2003. Le corps et ses sociologies. Nathan, Paris.

Durkheim, E. [1896] 1973. De la division du travail social. Ninth edition, Presses Universitaires de France, Paris.

Featherstone, M. 1991. Consumer Culture and Postmodernism. Sage, London.

Featherstone, M. and Hepworth, M. 1991. The mask of ageing and the postmodern life course. In Featherstone, M., Hepworth, M. and Turner, B. S. (eds.), The Body: Social Process and Cultural Theory. Sage, London, 371-89.

Foucault, M. 1976. La politique de la santé au XVIIIe siècle. In Dits et écrits II, 19761988. Gallimard, Paris, $13^{-27}$.

Gilleard, C. and Higgs, P. 2011 . Ageing abjection and embodiment in the fourth age. Journal of Aging Studies, 25, 2, $135^{-42 .}$.

Gish, J. A. and Vrkljan, B. 2016. Aging embodiment and the somatic work of getting into and out of a car. Journal of Aging Studies, 36, 33-46.

Goffman, E. 1974. Les rites d'interaction. Editions de Minuit, Paris.

Goffman, E. [1963] 1975. Stigmate. Les usages sociaux des handicaps. Editions de Minuit, Paris.

Grippo, K. P. and Hill, M. S. 20o8. Self-objectification, habitual body monitoring, and body dissatisfaction in older European American women: exploring age and feminism and moderators. Body Image, 5, 2, 173-82.

Grogan, S. 2008. Body Image: Understanding Body Dissatisfaction in Men, Women, and Children. Routledge, New York.

Halliwell, E. and Dittmar, H. A. 2003. Qualitative investigation of women's and men's body image concerns and their attitudes toward aging. Sex Roles, 49, $11 / 12,675^{-84}$.

Hurd, L. 200o. Older women's body image and embodied experience: an exploration. Journal of Women and Aging, 1 2, 3/4, 77-97.

Hurd Clarke, L. 2001. Older women's bodies and the self: the construction of identity in later life. Ageing $\mathcal{E}^{2}$ Society, 38, 4, 441-64.

Hurd Clarke, L. and Griffin, M. 2008. Visible and invisible ageing: beauty work as a response to ageism. Ageing $\mathcal{E}^{2}$ Society, 28, 5, 653-74.

Hurd Clarke, L. and Korotchenko, A. 2011 . Aging and the body: a review. Canadian Journal of Aging, 3o, 3, 495-510.

Kaufman, S. R. 1986. The Ageless Self. University of Wisconin Press, Madison, Wisconin.

Kozar, J. M. and Damhorst, M. L. 20o9. Comparison of the ideal and real body as women age: relationships to age identity, body satisfaction and importance, and attention to models in advertising. Clothing and Textiles Research Journal, 27, 3, 197-210.

Krekula, C. 2007. The intersection of age and gender: reworking gender theory and social gerontology. Current Sociology, 55, 2, $155^{-71 .}$

Laliberte Rudman, D. 2015. Embodying positive aging and neoliberal rationality: talking about the aging body within narratives of retirement. Journal of Aging Studies, 34, 10-20.

Le Breton, D. 1990. Anthropologie du corps et modernité. Presses Universitaires de France, Paris.

Macia, E. 2013. Dans la peau d'une femme de plus de 65 ans. Armand Colin, Paris. 


\section{Enguerran Macia et al.}

Macia, E., Duboz, P. and Chevé, D. 2015. The paradox of impossible beauty. Body changes and beauty practice in ageing women. Journal of Women and Aging, 27, $2,174-87$.

Macia, E., Duboz, P., Montepare, J. M. and Gueye, L. 201 2. Age identity, self-rated health and life satisfaction among older adults in Dakar, Senegal. European Journal of Ageing, 9, 3, 243-53.

Macia, E., Duboz, P., Montepare, J. M. and Gueye, L. 2015 a. Social representations of older adults in Dakar, Senegal. Ageing E Society, 35, 2, 405-27.

Macia, E., Duboz, P., Montepare, J. M. and Gueye, L. $2015^{b}$. Exploring life satisfaction among older adults in Dakar. Journal of Cross-cultural Gerontology, 3o, 4, $377-91$.

Makoni, S. and Stroeken, K. 2002. Ageing in Africa: Sociolinguistic and Anthropological Approaches. Ashgate, London.

Mauss, M. [1924] 1950. Rapports réels et pratiques de la psychologie et de la sociologie. In Sociologie et anthropologie. Presses Universitaires de France, Paris, 280-310.

Mauss, M. [1936] 1950. Les techniques du corps. In Sociologie et anthropologie. Presses Universitaires de France, Paris, 363-83.

Montepare, J. M. 2006. Body consciousness across the adult years: variations in actual and subjective age. Journal of Adult Development, 13, 2, 102-7.

Morell, C. 2003. Empowerment and long-living women: return to the rejected body. Journal of Aging Studies, 1 7, 1, 69-85.

Ndiaye, S. and Ayad, M. 2006. Enquête démographique et de santé au Sénégal 2005. Centre de Recherche pour le Développement Humain, Dakar, Senegal and ORC Macro, Calverton, Maryland, USA [Accessed 8 February 2013].

Öberg, P. 1996. The absent body - a social gerontological paradox. Ageing EV Society, 16, $701-19$.

Öberg, P. and Tornstam, L. 1999. Body images among men and women of different ages. Ageing E Society, 19, 5, 629-44.

Roy, M. and Payette, H. 2012. The body image construct among Western seniors: a systematic review of the literature. Archives of Gerontology and Geriatrics, 55, 3, $5^{\mathrm{O}} 5^{-21}$.

Schilder, P. [1950] 1968. L'image du corps. Gallimard, Paris.

Schwaiger, L. 2006. To be forever young? Toward reframing corporeal subjectivity in maturity. Journal of Ageing $\mathcal{E}^{2}$ Later Life, 1, 1, $11-41$.

Slevin, K. F. 2008. Disciplining bodies: the aging experiences of older heterosexual and gay men. Generations, $\mathbf{3 2}^{2}, 1,36-4^{2}$.

Sontag, S. 1972. The double standard of aging. Saturday Review of Society, 23 September, 29-38.

Sparkes, A. C. and Day, J. 2016. Aging bodies and desistance from crime: insights from the life stories of offenders. Journal of Aging Studies, 36, 47-58.

Tiggemann, M. 2004. Body image across the adult life span: stability and change. Body Image, 1, 1, 29-41.

Tulle, E. 2008. The ageing body and the ontology of ageing: athletic competence in later life. Body and Society, 14, 3, 1-19.

Turner, B. S. 1994. The postmodernisation of the life course: towards a new social gerontology. Australian Journal on Ageing, 13, 3, 109-11.

Twigg, J. 2004. The body, gender and age: feminist insights in social gerontology. Journal of Aging Studies, 18, 59-73.

Twigg, J. and Majima, S. 2014. Consumption and the constitution of age: expenditure patterns on clothing, hair and cosmetics among post-war 'baby boomers'. Journal of Aging Studies, 3o, 23-32. 
United Nations 2016. Human Development Report 2015. Available online at http://hdr. undp.org/sites/default/files/2015_human_development_report.pdf [Accessed 17 March 2017].

Vallerand, R. J. 1989. Vers une méthodologie de validation transculturelle de questionnaires psychologiques: implications pour la recherche en langue française. Canadian Psychology/Psychologie Canadienne, 3o, 4, 662-8o.

Werner, J.-F. 1997. Itinéraires individuels à la marge. Etudes de cas sénégalais. In Marie, A. (ed.), L'Afrique des individus. Karthala, Paris, 367-403.

Accepted 27 October 2017 ; first published online 4 December 2017

Address for correspondence:

Enguerran Macia,

UMI 3189 Environnement, santé, sociétés (CNRS/Université Cheikh Anta

Diop/Université de Bamako/CNRST Burkina-Faso),

Faculté de Médecine, de Pharmacie et d'Odontostomatologie,

Université Cheikh Anta Diop de Dakar (UCAD),

BP 5005, Dakar-Fann, Senegal

E-mail: enguerranmacia@gmail.com 